\title{
PD-L1, FGFR1, PIK3CA, PTEN, and p16 expression in pulmonary emphysema and chronic obstructive pulmonary disease with resected lung squamous cell carcinoma
}

Ken Arimura ${ }^{1 *}$, Yasuo Sekine ${ }^{2 *}$, Kenzo Hiroshima ${ }^{3}$, Satoru Shimizu ${ }^{4}$, Noriyuki Shibata $^{5}$, Mitsuko Kondo ${ }^{1}$, Kiyoshi Takeyama ${ }^{1}$ and Etsuko Tagaya ${ }^{1}$

\begin{abstract}
Background: Emphysema and chronic obstructive pulmonary disease (COPD) are well known independent risk factors for lung cancer. However, the developmental mechanisms between emphysema/COPD and lung cancer remain unknown. The purpose of this study was to evaluate PD-L1, FGFR1, PIK3CA, PTEN, and p16 expression in squamous cell carcinoma (SCC) associated with emphysema/COPD.
\end{abstract}

Methods: A total of 59 patients with squamous cell lung carcinoma (SCC) resected between 2008 and 2012 were retrospectively reviewed. Emphysema was assessed according to the Goddard score. Total severity was divided into none-mild (0-7), moderate (8-15), and severe $(\geq 16)$. Local severity around the existing tumor was divided into no emphysema (0) and presence of emphysema (1-4). COPD severity was based on the Global Initiative for Chronic Obstructive Lung Disease (GOLD) criteria. PD-L1, FGFR1, PIK3CA, PTEN, and p16 expression were evaluated by immunohistochemistry (IHC). Expression level was classified as tumor cells (TC) $3(\geq 50 \%)$, TC2 (5-49\%), TC1 (1-4\%), or TCO $(<1 \%)$, and as tumor-infiltrating immune cells (IC) 3 ( $\geq 50 \%)$, IC2 (5-49\%), IC1 (1-4\%), or ICO (<1\%) for PDL1. Expression level was compared between none-mild/moderate-severe total emphysema, no/presence of local emphysema, no COPD/COPD, and GOLD 1/GOLD 2, 3.

Results: PD-L1 expression was significantly correlated with severity of emphysema in TC0, 1, 2 vs. TC3 ( $P=0.012)$. PD-L1 was significantly higher inversely in none-mild emphysema compared to moderate-severe $(95 \% \mathrm{Cl}, 0.061-5.852$, $P=0.045$ ). There were no other significant associations between PD-L1, FGFR1, PIK3CA, PTEN, and p16 expression and total/local severity of emphysema or presence of COPD/GOLD stage.

Conclusions: PD-L1 expression in SCC was correlated with severity of emphysema in TCO, 1, 2 vs. TC3 and more frequent in none-mild emphysema than moderate-severe emphysema.

Keywords: PD-L1, Lung squamous cell carcinoma, Emphysema, COPD

\footnotetext{
*Correspondence: arimuraken@gmail.com; sekine.yasuo@twmu.ac.jp

${ }^{1}$ Department of Respiratory Medicine, Tokyo Women's Medical University,

Tokyo, Japan

${ }^{2}$ Departments of Thoracic Surgery, Tokyo Women's Medical University

Yachiyo Medical Center, Chiba, Japan

Full list of author information is available at the end of the article
}

(c) The Author(s). 2019 Open Access This article is distributed under the terms of the Creative Commons Attribution 4.0 International License (http://creativecommons.org/licenses/by/4.0/), which permits unrestricted use, distribution, and reproduction in any medium, provided you give appropriate credit to the original author(s) and the source, provide a link to the Creative Commons license, and indicate if changes were made. The Creative Commons Public Domain Dedication waiver (http://creativecommons.org/publicdomain/zero/1.0/) applies to the data made available in this article, unless otherwise stated. 


\section{Background}

Lung cancer is the primary cause of cancer-related death worldwide. It is well known that smoking is a major risk factor for lung cancer [1]. Smoking causes emphysema and chronic obstructive pulmonary disease (COPD) [2, 3]. Several studies have found that emphysema and COPD are independent risk factors for lung cancer [4-6], especially squamous cell lung carcinoma (SCC) $[7,8]$.

The efficacy of immune checkpoint inhibitors has been established for SCC that express programmed death ligand 1 (PD-L1) $[9,10]$. Although targeted therapy against adenocarcinoma with epidermal growth factor receptor (EGFR) gene mutation or anaplastic lymphoma kinase (ALK) and ROS1 proto-oncogene receptor tyrosine kinase (ROS1) rearrangements have shown dramatic effects [11-13], few targeted therapies against SCC have been identified. Previous reports have suggested that potential targets for therapy against SCC including fibroblast growth factor receptor 1 (FGFR1), phosphatidylinositol - 4,5 - bisphosphate 3 - kinase catalytic subunit alpha (PIK3CA), phosphatase and tensin homolog (PTEN), and p16 [14-17].

The genetic causes of emphysema and COPD are largely unknown $[18,19]$. Furthermore, the developmental pathway between COPD and non-small cell lung cancer (NSCLC) remains elusive [20-22]. The purpose of this study was to evaluate PD-L1, FGFR1, PIK3CA, PTEN, and p16 expression in SCC associated with emphysema and COPD.

\section{Methods}

\section{Ethical considerations}

This was a retrospective study approved by the institutional review board (Date of approval: Dec 27, 2012, approval number: 2693) of Tokyo Women's Medical University Hospital. Written informed consent was obtained from all patients before tumors were resected and additional consent was waived.

\section{Patients population and samples}

This study included 59 patients who underwent surgery for SCC between February 2008 and December 2012 at Tokyo Women's Medical University, Yachiyo Medical Center. All patients had computerized tomography (CT) and respiratory function tests to assess the suspected malignancy and determine eligibility for surgical intervention prior to surgery. Resected tumors were immediately fixed with $10 \%$ formalin, stained with hematoxylin and eosin (HE) and prepared for immunohistochemistry (IHC) staining.

\section{Definition of emphysema}

The severity of emphysema on CT was visually assessed by two independent pulmonologists according to the
Goddard scoring system [23, 24]. Low attenuation area (LAA) on six images of three lung slices (the right and left lungs were evaluated separately) were analyzed for each patient [25]. Each image was scored as follows: score 0 (no LAA), score 1 (LAA of 1-25\%), score 2 (LAA of 26-50\%), score 3 (LAA of $51-75 \%$ ), and score 4 (LAA of $\geq 76 \%$ ) [23]. Total severity score was categorized into one of three groups as follows: none-mild (0-7), moderate (8-15), and severe $(\geq 16)$. Local severity score around the tumor was classified as no-emphysema (0) and presence of emphysema (1-4).

\section{Definition of COPD}

Respiratory function tests were performed to assess the eligibility for surgery. Diagnosis of COPD was based on the Global Initiative for Chronic Obstructive Lung Disease (GOLD) criteria after confirming the presence of persistent airflow limitation by a post-bronchodilator forced expiratory volume in one second (FEV1)/forced vital capacity $(\mathrm{FVC})<70 \%$ [26]. The severity of air flow limitation was classified using the GOLD staging criteria with \% predicted FEV1, as follows: GOLD 1 ( $\geq 80 \%)$, GOLD 2 (50-79\%), GOLD 3 (30-49\%), and GOLD $4(<30 \%)$ [26].

\section{Molecular and IHC analysis}

PD-L1, FGFR1, PIK3CA, PTEN, and p16 expression was evaluated by IHC staining of archived resected samples. IHC was performed with the following antibodies: PDL1 (clone SP-142, diluted 1:100; Ventana Medical System, Arizona, USA), FGFR-1 (polyclonal, diluted 1: 400; Abcam, Cambridge, UK), PIK3CA (Recombinant, diluted 1:400; Abcam), PTEN (clone 138G6, diluted 1: 200; Cell Signaling, Massachusetts, USA), and p16 (Recombinant, diluted 1:2000; Abcam).

To improve the expression, the tissues were pretreated with microwaves in ethylenediaminetetraacetic acid for PD-L1, or in retrieval solution (DAKO Target Retrieval Solution pH 9, Glostrup, Denmark) for FGFR1 in citrate buffer for PTEN and p16, before staining. Positive controls in IHC protocols were specimens from pulmonary SCC where the target molecules have been confirmed to be positive. To validate the specificity of the secondary antibody, negative reaction control sections obtained by omission of the primary antibody were used. IHC expression was evaluated by one experienced pathologist and pulmonologist in a blinded fashion. Each expression of tumor cells was classified by staining as follows: tumor cells (TC) 3 ( $\geq 50 \%)$, TC2 (5-49\%), TC1 (1-4\%), and TC0 (<1\%) [27]. Furthermore, tumor-infiltrating immune cells were also evaluated for PD-L1 as follows: immune cells (IC) 3 ( $\geq 50 \%)$, IC2 (5-49\%), IC1 (1-4\%), and IC0 (<1\%). Immune cells were evaluated only for PD-L1, based on a 
previous study [27]. If the score did not initially agree between evaluators, a discussion was initiated. Analysis of PD-L1 expression was as follows: TC0 vs. TC1, 2, 3, TC0, 1 vs. TC 2,3 , TC0, 1, 2 vs. TC3 and IC0 vs. IC1, 2, 3, IC0, 1 vs. IC 2, 3, IC0, 1, 2 vs. IC3. Analysis of FGFR1, PIK3CA, PTEN, and p16 expression was as follows: TC0 vs TC1, 2, 3.

\section{Data analysis}

Each expression of IHC was compared between none-mild $(0-7)$ and mild-severe (8-24) emphysema groups of total Goddard scoring, no-emphysema (0) and presence of emphysema (1-4) tumor area groups, non-COPD and COPD groups, and GOLD 1 and GOLD 2, 3 groups. Data analysis was carried out using Statistical Analysis System (SAS institute, Cary, NC) and Graph Pad PRISM (GraphPad Software, La Jolla, CA). $P$ values $<0.05$ were regarded as statistically significant. The $t$-test was used to compare between each expression and Goddard score. Chi-squared test was used to compare between each expression and severity of emphysema, presence of COPD/Gold staging. Groups were compared using 95\% confidence intervals (CI).

\section{Results}

Baseline characteristics and molecular classification by staining

A total of 59 patients with surgically resected SCC were eligible for this study. Patient baseline characteristics included sex, median age, smoking history, histology, pathological stage, total severity of emphysema, local severity of emphysema, presence of COPD, and GOLD stage (Table 1). There were no significant differences between total emphysema status, local emphysema status, COPD status and GOLD stage based on sex, smoking history and stage (Table 2). Classifications of TC0-3, IC0-3 for PD-L1 (Fig. 1) and of TC0-3 for FGFR1, PIK3CA, PTEN, and p16 expression were recorded (Table 3 ).

\section{Comparison between each classification of expression and severity of emphysema}

IHC expression of each molecular antibody was compared to total/local severity of emphysema (Table 4). PD-L1 expression was significantly correlated with total severity of emphysema in TC0, 1,2 vs. TC3 $(P=0.012)$. However, there was no other significant association between classification of expression and total/local severity of emphysema. Since there was significant association in total severity of emphysema, the results between TC0, 1, 2 (PD-L1 0-49) and TC3 (PD-L1 50-100) for total severity of emphysema were compared. There was significant difference between groups (95\% CI: $0.061-5.852, P=0.045$ ) (Fig. 2).
Table 1 Patient characteristics

\begin{tabular}{|c|c|}
\hline Patient Characteristics & No (\%) \\
\hline Patients & 59 \\
\hline Median age (range) & $72.7(56-85)$ \\
\hline \multicolumn{2}{|l|}{ Sex } \\
\hline Male & $50(84.7)$ \\
\hline Female & $9(15.3)$ \\
\hline \multicolumn{2}{|l|}{ Smoking history } \\
\hline Ever & 57 (96.6) \\
\hline Never & $2(3.4)$ \\
\hline Median pack year (range) & $58.9(0-184)$ \\
\hline \multicolumn{2}{|l|}{ Histology } \\
\hline Squamous cell carcinoma & $59(100)$ \\
\hline \multicolumn{2}{|l|}{ Pathological stage } \\
\hline । & $38(64.4)$ \\
\hline$\|$ & $16(27.1)$ \\
\hline III & $4(6.8)$ \\
\hline recurrence & $1(1.7)$ \\
\hline \multicolumn{2}{|l|}{ Severity of emphysema } \\
\hline mild & $40(67.8)$ \\
\hline moderate & $14(23.7)$ \\
\hline severe & $5(8.5)$ \\
\hline \multicolumn{2}{|l|}{ Local severity of emphysema } \\
\hline non & $23(39.0)$ \\
\hline presence & $36(61.0)$ \\
\hline \multicolumn{2}{|l|}{ Presence of COPD } \\
\hline No COPD & $29(49.2)$ \\
\hline COPD & $30(50.8)$ \\
\hline \multicolumn{2}{|l|}{ Staging of GOLD } \\
\hline GOLD1 & $37(62.7)$ \\
\hline GOLD2 & $21(35.6)$ \\
\hline GOLD3 & $1(1.7)$ \\
\hline
\end{tabular}

COPD chronic obstructive pulmonary disease, GOLD Global Initiative for Chronic Obstructive Lung Disease

\section{Comparison between each classification of expression and presence of COPD/ GOLD stage}

The results of each classification of expression and presence of COPD/Gold stage was compared (Table 4). There was no significant association between classification of expression and presence of COPD/GOLD stage.

\section{Discussion}

Few reports have investigated the associations between TC, PD-L1, emphysema, mutational analysis, and COPD in NSCLC [28, 29]. One study on lung adenocarcinoma found that patients with emphysema had more PD-L1 positive cells than patients without 
Table 2 Comparison of patient characteristics based on total emphysema, local emphysema, COPD, and GOLD stage

\begin{tabular}{|c|c|c|c|c|c|c|c|c|c|c|c|c|}
\hline Factors & $\begin{array}{l}\text { none- } \\
\text { mild }\end{array}$ & $\begin{array}{l}\text { moderate- } \\
\text { severe }\end{array}$ & $P$ value & $\begin{array}{l}\text { No Local } \\
\text { emphysema }\end{array}$ & $\begin{array}{l}\text { Local } \\
\text { emphysema }\end{array}$ & $P$ value & $\begin{array}{l}\text { No } \\
\text { COPD }\end{array}$ & COPD & $P$ value & GOLD1 & $\begin{array}{l}\text { GOLD2, } \\
3\end{array}$ & $P$ value \\
\hline \multicolumn{13}{|l|}{ SEX } \\
\hline Male & 33 & 17 & 0.78 & 18 & 32 & 0.54 & 26 & 24 & 0.59 & 34 & 16 & 0.14 \\
\hline Female & 7 & 2 & & 5 & 4 & & 3 & 6 & & 3 & 6 & \\
\hline \multicolumn{13}{|l|}{ Smoking } \\
\hline Never & 2 & 0 & 0.61 & 2 & 0 & 0.2 & 2 & 0 & 0.34 & 2 & 0 & 0.54 \\
\hline Ever & 38 & 19 & & 21 & 36 & & 27 & 30 & & 35 & 22 & \\
\hline \multicolumn{13}{|l|}{ Stage } \\
\hline I & 27 & 11 & 0.63 & 16 & 22 & 0.84 & 21 & 17 & 0.62 & 28 & 10 & 0.17 \\
\hline$\|$ & 10 & 6 & & 5 & 11 & & 7 & 9 & & 7 & 9 & \\
\hline III & 3 & 1 & & 2 & 2 & & 1 & 3 & & 2 & 2 & \\
\hline recurrence & 0 & 1 & & 0 & 1 & & 0 & 1 & & 0 & 1 & \\
\hline
\end{tabular}

emphysema [28]. Another study on NSCLC showed that PIK3CA expression was significantly associated with COPD [29].

In this study, PD-L1 expression was significantly correlated with severity of total emphysema in TC0, 1, 2 vs. TC3 $(P=0.012)$. Furthermore, there was a significant difference inversely in total severity of emphysema between TC0, 1, 2 (PD-L1 0-49) and TC3 (PD-L1 50-100) (95\% CI: $0.061-5.852, P=0.045$ ). There were no other significant associations between classification of expression and total/local severity of emphysema, and between classification of expression and presence of COPD/ GOLD stage. These results differ from previous studies on the associations between PD-L1 expression and emphysema in patients with lung adenocarcinoma [28], and between PIK3CA gene mutation and COPD in patients with NSCLC [29]. One explanation for this discrepancy is that our study focused on SCC while other studies focused on lung adenocarcinoma or NSCLC. Another is that our study focused on protein expression while other study focused on the gene mutation. These differences may have influenced the results and may
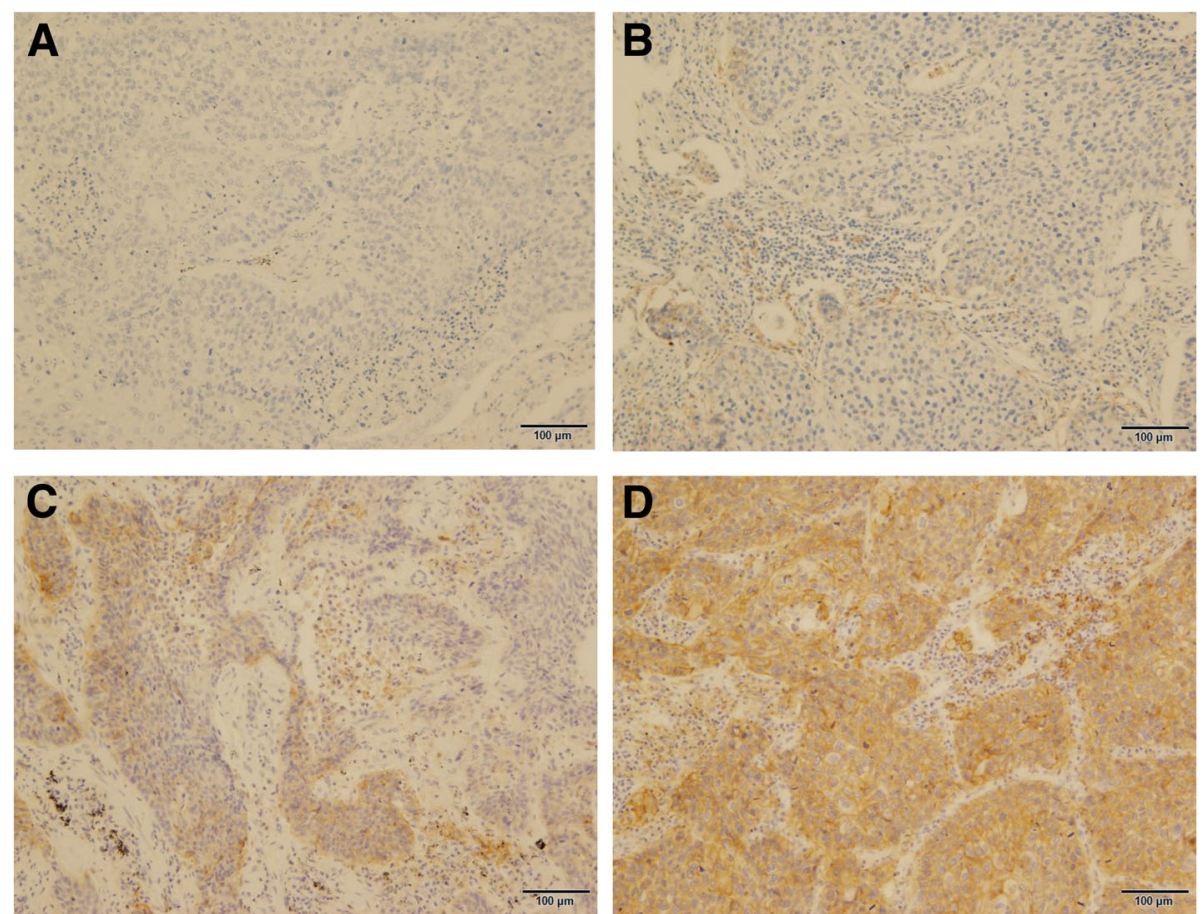

Fig. 1 Representative image of PD-L1 expression for each staining level (10X). A TC0 and ICO (< 1\%), B TC1 and IC1 (1-4\%), C TC2 and IC2 (5-49\%), D TC3 and IC3 (50-100\%). PD-L1 programmed death ligand 1, TC tumor cells, IC immune cell 
Table 3 Classification of each expression

\begin{tabular}{|c|c|c|c|c|c|}
\hline Classify of expression (\%) & PD-L1 & FGFR1 & PIK3CA & PTEN & p16 \\
\hline $\mathrm{TCO}$ & $7(11.9)$ & $26(44.1)$ & $55(93.2)$ & $35(59.3)$ & $22(37.3)$ \\
\hline TC1 & $12(20.3)$ & $15(25.4)$ & $3(5.1)$ & $8(13.6)$ & $19(32.2)$ \\
\hline TC2 & $17(28.8)$ & $17(28.8)$ & $1(1.7)$ & $15(25.4)$ & $16(27.1)$ \\
\hline TC3 & $23(39.0)$ & $1(1.7)$ & $0(0)$ & $1(1.7)$ & $2(3.4)$ \\
\hline ICO & $1(1.7)$ & & & & \\
\hline $\mathrm{IC} 1$ & $2(3.4)$ & & & & \\
\hline IC2 & $25(42.4)$ & & & & \\
\hline IC3 & $31(52.5)$ & & & & \\
\hline
\end{tabular}

PD-L1 programmed death ligand 1, FGFR1 fibroblast growth factor receptor 1, PIK3CA phosphatidylinositol-4,5-bisphosphate 3-kinase catalytic subunit alpha, PTEN phosphatase and tensin homolog, TC tumor cells, IC immune cell

Table 4 Comparison between each classification of expression and severity of emphysema, presence of COPD, GOLD staging

\begin{tabular}{|c|c|c|c|c|c|c|c|c|c|c|c|c|}
\hline \multirow[b]{2}{*}{ Classify of expression } & \multicolumn{2}{|c|}{ Total severity of emphysema } & \multirow[b]{2}{*}{$P$ value } & \multicolumn{2}{|c|}{ Local severity of emphysema } & \multirow{2}{*}{$P$ value } & \multicolumn{2}{|c|}{ Presence of COPD } & \multirow[b]{2}{*}{$P$ value } & \multicolumn{2}{|c|}{ Staging of GOLD } & \multirow[b]{2}{*}{$P$ value } \\
\hline & none-mild & moderate-severe & & none & present & & No COPD & COPD & & $\overline{\text { GOLD1 }}$ & $\overline{\text { GOLD2,3 }}$ & \\
\hline \multicolumn{13}{|l|}{ PD-L1 } \\
\hline TCO & 6 & 1 & 0.28 & 5 & 2 & 0.06 & 3 & 4 & 0.72 & 5 & 2 & 0.61 \\
\hline $\mathrm{TC} 1,2,3$ & 34 & 18 & & 18 & 34 & & 26 & 26 & & 32 & 20 & \\
\hline $\mathrm{TC} 0,1$ & 14 & 5 & 0.5 & 9 & 10 & 0.36 & 7 & 12 & 0.19 & 11 & 8 & 0.6 \\
\hline $\mathrm{TC2}, 3$ & 26 & 14 & & 14 & 26 & & 22 & 18 & & 26 & 14 & \\
\hline $\mathrm{TC} 0,1,2$ & 20 & 16 & 0.012 & 13 & 23 & 0.57 & 17 & 19 & 0.71 & 22 & 14 & 0.75 \\
\hline TC3 & 20 & 3 & & 10 & 13 & & 12 & 11 & & 15 & 8 & \\
\hline ICO & 1 & 0 & 0.49 & 1 & 0 & 0.2 & 0 & 1 & 0.32 & 1 & 0 & 0.44 \\
\hline IC $1,2,3$ & 39 & 19 & & 22 & 36 & & 29 & 29 & & 36 & 22 & \\
\hline $\mathrm{ICO}, 1$ & 2 & 0 & 0.32 & 2 & 0 & 0.07 & 0 & 2 & 0.16 & 2 & 0 & 0.27 \\
\hline $\mathrm{IC} 2,3$ & 38 & 19 & & 21 & 36 & & 29 & 28 & & 35 & 22 & \\
\hline $\mathrm{IC} 0,1,2$ & 20 & 7 & 0.34 & 14 & 13 & 0.06 & 16 & 11 & 0.15 & 18 & 9 & 0.56 \\
\hline IC3 & 20 & 12 & & 9 & 23 & & 13 & 19 & & 19 & 13 & \\
\hline \multicolumn{13}{|l|}{ FGFR1 } \\
\hline TCO & 17 & 9 & 0.72 & 8 & 18 & 0.25 & 13 & 13 & 0.91 & 14 & 12 & 0.21 \\
\hline $\mathrm{TC} 1,2,3$ & 23 & 10 & & 15 & 18 & & 16 & 17 & & 23 & 10 & \\
\hline \multicolumn{13}{|l|}{ PIK3CA } \\
\hline TCO & 36 & 19 & 0.15 & 22 & 33 & 0.55 & 28 & 27 & 0.32 & 33 & 22 & 0.11 \\
\hline $\mathrm{TC} 1,2,3$ & 4 & 0 & & 1 & 3 & & 1 & 3 & & 4 & 0 & \\
\hline \multicolumn{13}{|l|}{ PTEN } \\
\hline TCO & 23 & 12 & 0.68 & 17 & 18 & 0.07 & 16 & 19 & 0.52 & 20 & 15 & 0.29 \\
\hline $\mathrm{TC} 1,2,3$ & 17 & 7 & & 6 & 18 & & 13 & 11 & & 17 & 7 & \\
\hline \multicolumn{13}{|l|}{ p16 } \\
\hline TCO & 13 & 9 & 0.27 & 10 & 12 & 0.43 & 14 & 8 & 0.09 & 12 & 10 & 0.32 \\
\hline $\mathrm{TC} 1,2,3$ & 27 & 10 & & 13 & 24 & & 15 & 22 & & 25 & 12 & \\
\hline
\end{tabular}

COPD Chronic obstructive pulmonary disease, GOLD Global Initiative for Chronic Obstructive Lung Disease, PD-L1 Programmed death ligand 1, TC Tumor cells, IC Immune cells, FGFR1 Fibroblast growth factor receptor 1, PIK3CA Phosphatidylinositol-4,5-bisphosphate 3-kinase catalytic subunit alpha, PTEN Phosphatase and tensin homolog 


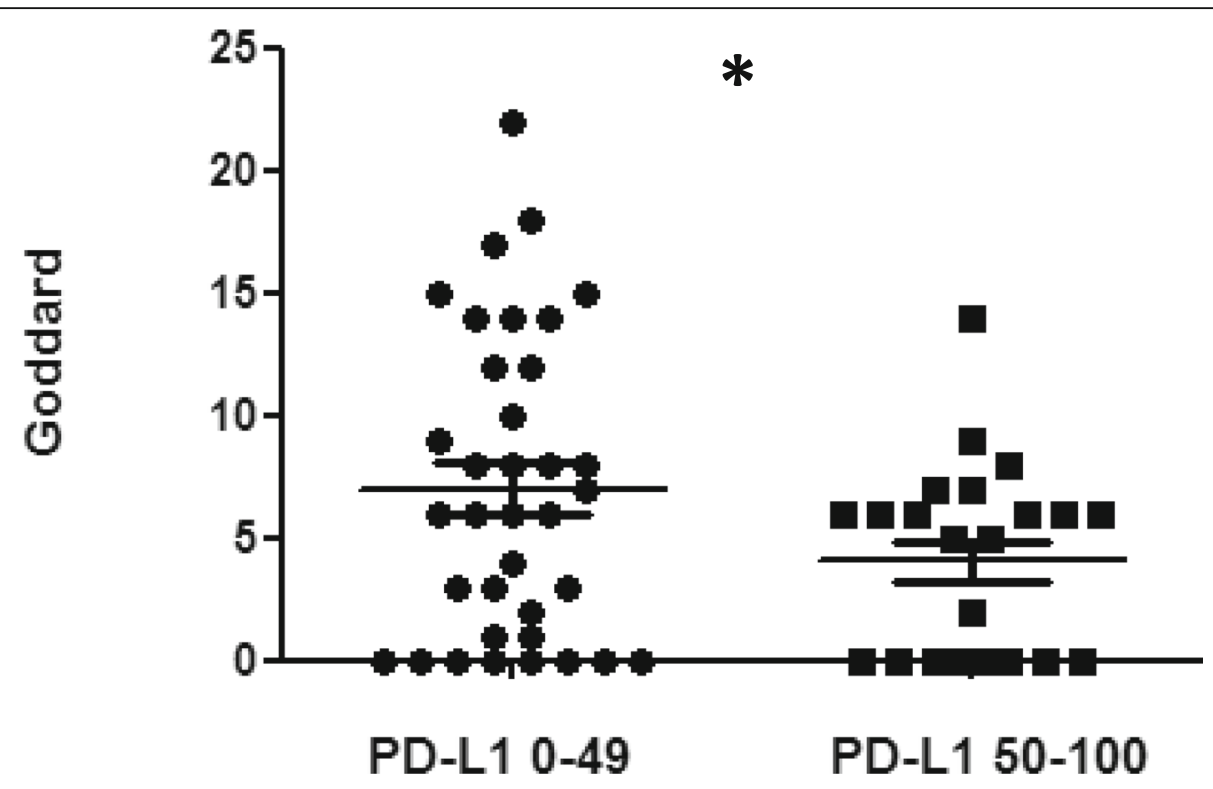

Fig. 2 Comparison between TC0, 1, 2 (PD-L1 0-49) and TC3 (PD-L1 50-100) based on Goddard score PD-L1 expression was more than 50\% when Goddard score was low $\left(95 \% \mathrm{Cl}: 0.061-5.852,{ }^{*} P=0.045\right)$. PD-L1 programmed death ligand 1

account for the differences in PD-L1 expression and PIK3CA.

This study identified for the first time a significant association between high expression of PD-L1 ( $\geq 50 \%)$ and none-mild emphysema in SCC. However, the mechanism behind this association remains unknown. Previous studies have shown an increased proportion of PD-1 positive CD8 T-cells in the lungs of patients with COPD lung such as lung emphysema. This appeared to contribute to dysfunctional of CD8 T-cells [30, 31]. Our findings suggest that tumor need not escape from $\mathrm{CD} 8$ T-cell attack, particularly given the low expression of PD-L1 when emphysema is moderate-severe. On the contrary, if a tumor escapes CD8 T-cell attack, it might be attributed to high expression of PD-L1 in none-mild emphysema.

This study found that none-mild emphysema was an independent predictive factor of high PD-L1 expression $(\geq 50 \%)$. This result suggests the utility of non-invasive ways of predicting high expression of PD-L1 ( $\geq 50 \%$ ), such as CT imaging. CT imaging may also be an effective way of deciding to use immune checkpoint inhibitors $[9,10]$ in patients with SCC before determining PD-L1 expression with IHC. This might prevent significant life threatening events associated with surgery and bronchoscopy, such as decreasing respiratory function, embolism, bleeding, and pneumothorax. In addition, this might lead to insights regarding the mechanistic correlation between PD-L1 expression and emphysema.

This study had several limitations. First, this was a retrospective study performed at a single institution, which may have influenced the results. A prospective multicenter randomized control trial is needed to confirm our results. Second, although this study shows an association between each expression and Goddard, COPD, and GOLD stage, the associations between those and overall survival rates remain unknown. An evaluation of overall survival is needed. Third, although LAA was evaluated with Goddard criteria, it is unclear if the automated evaluation for LAA [32] would provide the same results. Additional studies are needed to determine what methods are most appropriate for evaluating LAA.

\section{Conclusion}

In conclusion, there was a significant association between TC0, 1, 2 vs. TC3 groups and none-mild vs. moderate-severe emphysema groups in patients who underwent surgical resection of lung SCC. PD-L1 expression was significant higher in none-mild emphysema than in moderate-severe emphysema. There was no significant association between any other classification of expression for PD-L1, FGFR1, PIK3CA, PTEN, p16 and total/local severity of emphysema, between classification of expression for PD-L1, FGFR1, PIK3CA, PTEN, p16 and presence of COPD/ GOLD staging. Further studies are needed to evaluate overall survival between classification of each expression and total/local severity of emphysema, presence of COPD/ GOLD stage.

Abbreviations

COPD: Chronic obstructive pulmonary disease; GOLD: Global Initiative for Chronic Obstructive Lung Disease; PD-L1: Programmed death ligand 1; SCC: Squamous cell carcinoma 


\section{Acknowledgements}

The authors greatly appreciate Mr. Mizuho Karita and Mr. Masaki Takahashi for their technical assistance.

\section{Authors' contributions}

Conception and design: KA, YS; Acquisition of data: KA, YS; Analysis of data: $\mathrm{KA}, \mathrm{SS}, \mathrm{MK}$; Immunohistochemistry staining: KA, KH, NS; Manuscript the article: KA; Revision and Edition the article: KA, YS, KH, KT, ET; All authors read and approved the manuscript.

\section{Funding}

This study was supported in part by KAKENHI grant number 26462139 (to YS). The grant contributed to IHC staining but did not play any roles in the design of the study, data collection, analysis, and interpretation of data in this manuscript.

\section{Availability of data and materials}

The dataset supporting the conclusions of this study is presented in this manuscript. The clinical detail dataset is available with author and corresponding author, not publicly available.

\section{Ethics approval and consent to participate}

This study was approved by the institutional review board (Date of approval: Dec 27, 2012, approval number: 2693) of Tokyo Women's Medical University Hospital. Informed consent was obtained from all patients before tumors were resected.

\section{Consent for publication}

Not applicable

\section{Competing interests}

The authors have no competing interests.

\section{Author details}

${ }^{1}$ Department of Respiratory Medicine, Tokyo Women's Medical University, Tokyo, Japan. ${ }^{2}$ Departments of Thoracic Surgery, Tokyo Women's Medical University Yachiyo Medical Center, Chiba, Japan. ${ }^{3}$ Departments of Pathology, Tokyo Women's Medical University Yachiyo Medical Center, Chiba, Japan. ${ }^{4}$ Departments of Medical Education, Tokyo Women's Medical University School of Medicine, Tokyo, Japan. ${ }^{5}$ Human and Experimental Pathology and Neuroscience, Tokyo Women's Medical University School of Medicine, Tokyo, Japan

Received: 15 October 2018 Accepted: 2 August 2019

Published online: 03 September 2019

\section{References}

1. Hackshaw AK, Law MR, Wald NJ. The accumulated evidence on lung cancer and environmental tobacco smoke. BMJ. 1997:315(7114):980-8.

2. Svanes $C$, et al. Early life origins of chronic obstructive pulmonary disease. Thorax. 2010;65(1):14-20.

3. de Marco R, et al. Risk factors for chronic obstructive pulmonary disease in a European cohort of young adults. Am J Respir Crit Care Med. 2011;183(7):891-7.

4. de Torres JP, et al. Assessing the relationship between lung cancer risk and emphysema detected on low-dose CT of the chest. Chest. 2007;132(6):1932-8.

5. Turner MC, et al. Chronic obstructive pulmonary disease is associated with lung cancer mortality in a prospective study of never smokers. Am J Respir Crit Care Med. 2007:176(3):285-90.

6. Wilson DO, et al. Association of radiographic emphysema and airflow obstruction with lung cancer. Am J Respir Crit Care Med. 2008;178(7):738-44.

7. Smith BM, et al. Lung cancer histologies associated with emphysema on computed tomography. Lung Cancer. 2012;76(1):61-6.

8. Papi A, et al. COPD increases the risk of squamous histological subtype in smokers who develop non-small cell lung carcinoma. Thorax. 2004;59(8):679-81.

9. Reck M, et al. Pembrolizumab versus chemotherapy for PD-L1-positive nonsmall-cell lung Cancer. N Engl J Med. 2016;375(19):1823-33.

10. Borghaei $\mathrm{H}$, et al. Nivolumab versus docetaxel in advanced nonsquamous non-small-cell lung Cancer. N Engl J Med. 2015;373(17):1627-39.

11. Maemondo M, et al. Gefitinib or chemotherapy for non-small-cell lung cancer with mutated EGFR. N Engl J Med. 2010;362(25):2380-8.
12. Takeuchi $\mathrm{K}$, et al. Multiplex reverse transcription-PCR screening for EML4-ALK fusion transcripts. Clin Cancer Res. 2008:14(20):6618-24.

13. Shaw AT, et al. Crizotinib in ROS1-rearranged non-small-cell lung Cancer. N Engl J Med. 2014:371(21):1963-71.

14. Cihoric $\mathrm{N}$, et al. Prognostic role of FGFR1 amplification in early-stage nonsmall cell lung cancer. Br J Cancer. 2014;110(12):2914-22.

15. Rekhtman N, et al. Clarifying the spectrum of driver oncogene mutations in biomarker-verified squamous carcinoma of lung: lack of EGFR/KRAS and presence of PIK3CA/AKT1 mutations. Clin Cancer Res. 2012;18(4):1167-76.

16. Yanagawa $\mathrm{N}$, et al. Loss of phosphatase and Tensin homolog protein expression is an independent poor prognostic marker in lung adenocarcinoma. J Thocac Oncol. 2012;7(10):1513-21.

17. Schneider F, et al. Morphological and molecular approach to synchronous nonsmall cell lung carcinomas: impact on staging. Mod Pathol. 2016;29(7):735-42.

18. Spira A, et al. Gene expression profiling of human lung tissue from smokers with severe emphysema. Am J Respir Cell Mol Biol. 2004;31(6):601-10.

19. Arimura $K$, et al. Chronic low-grade systemic inflammation causes DNA damage in the lungs of mice. Lung. 2012;190(6):613-20.

20. Adcock IM, Caramori G, Barnes PJ. Chronic obstructive pulmonary disease and lung cancer: new molecular insights. Respiration. 2011;81(4):265-84.

21. Sekine $Y$, et al. Early detection of COPD is important for lung cancer surveillance. Eur Respir J. 2012:39(5):1230-40.

22. Houghton AM. Mechanistic links between COPD and lung cancer. Nat Rev Cancer. 2013:13(4):233-45.

23. Goddard PR, et al. Computed tomography in pulmonary emphysema. Clin Radiol. 1982:33(4):379-87.

24. Sekine $Y$, et al. Detection of chronic obstructive pulmonary disease in community-based annual lung cancer screening: Chiba chronic obstructive pulmonary disease lung Cancer screening study group. Respirology. 2014;19(1):98-104.

25. Makita $\mathrm{H}$, et al. Characterisation of phenotypes based on severity of emphysema in chronic obstructive pulmonary disease. Thorax. 2007;62(11):932-7.

26. Claus F, et al. Eur Respir J. 2017:49(6):1700214. https://doi.org/10.1183/13993 003.50214-2017.

27. Fehrenbacher $L$, et al. Atezolizumab versus docetaxel for patients with previously treated non-small-cell lung cancer (POPLAR): a multicentre, openlabel, phase 2 randomised controlled trial. Lancet. 2016;387(10030):1837-46.

28. Toyokawa $\mathrm{G}$, et al. High frequency of programmed death-ligand 1 expression in emphysematous bullae-associated lung adenocarcinomas. Clin Lung Cancer. 2017;18(5):504-11.

29. Sawa K, et al. PIK3CA mutation as a distinctive genetic feature of non-small cell lung cancer with chronic obstructive pulmonary disease: a comprehensive mutational analysis from a multi-institutional cohort. Lung Cancer. 2017:112:96-101.

30. Bhat $T A$, et al. Immune dysfunction in patients with chronic obstructive pulmonary disease. Ann Am Thorac Soc. 2015;12(Suppl 2):S169-75.

31. McKendry RT, et al. Dysregulation of antiviral function of CD8(+) T cells in the chronic obstructive pulmonary disease lung. Role of the PD-1-PD-L1 Axis. Am J Respir Crit Care Med. 2016;193(6):642-51.

32. Mets $\mathrm{OM}$, et al. Visual versus automated evaluation of chest computed tomography for the presence of chronic obstructive pulmonary disease. PLoS One. 2012;7(7):e42227.

\section{Publisher's Note}

Springer Nature remains neutral with regard to jurisdictional claims in published maps and institutional affiliations.

Ready to submit your research? Choose BMC and benefit from

- fast, convenient online submission

- thorough peer review by experienced researchers in your field

- rapid publication on acceptance

- support for research data, including large and complex data types

- gold Open Access which fosters wider collaboration and increased citations

- maximum visibility for your research: over $100 \mathrm{M}$ website views per year

At $\mathrm{BMC}$, research is always in progress.

Learn more biomedcentral.com/submissions 